\title{
Evaluation of Efficacy of Mirtazapine on Pruritus and Serum Histamine and Serotonin Levels in Patients Undergoing Hemodialysis: A Before- After Pilot Clinical Trial
}

This article was published in the following Dove Press journal:

International Journal of Nephrology and Renovascular Disease

\author{
Maryam Mehrpooya' \\ Mahmoud Gholyaf ${ }^{2,3}$ \\ Fatemeh Yasrebifar' \\ Younes Mohammadi (iD) ${ }^{4}$ \\ Vida Sheikh (iD) ${ }^{2,3}$ \\ 'Department of Clinical Pharmacy, \\ School of Pharmacy, Hamadan University \\ of Medical Sciences, Hamadan, Iran; \\ ${ }^{2}$ Department of Internal Medicine, \\ School of Medicine, Hamadan University \\ of Medical Sciences, Hamadan, Iran; \\ ${ }^{3}$ Clinical Research Development Unit of \\ Shahid Beheshti Hospital, Hamadan \\ University of Medical Sciences, Hamadan, \\ Iran; ${ }^{4}$ Modeling of Noncommunicable \\ Diseases Research Center, School of \\ Public Health, Hamadan University of \\ Medical Sciences, Hamadan, Iran
}

Background: Although chronic kidney disease-associated pruritus (CKD-aP) remains a frequent and frustrating symptom in patients with advanced kidney diseases, its optimal treatments are not well defined. Based on its mechanism of action, as a histamine-1 (H1), 5-(hydroxytryptamine) HT2, and 5HT3-receptor blocker, mirtazapine may be effective in the treatment of CKD-aP. Hence, this study aimed to investigate the efficacy of mirtazapine for the treatment of pruritus in patients undergoing hemodialysis (HD).

Methods: A before-after clinical trial was conducted from September 2018 until March 2019, on 30 HD-patients that had been referred to the HD ward of a tertiary hospital, in Hamadan, Iran. After the 2-week washout period, mirtazapine was administered with a dosage of $15 \mathrm{mg} /$ day for an additional 2 weeks. At baseline and at each dialysis session, the effects of the mirtazapine on the pruritus severity based on the visual analogue scale (VAS) and degree of sleep interference resulting from the pruritus were asked and recorded. Additionally, at the baseline and the end of 2 weeks of treatment, the serum histamine and serotonin levels, as the main chemical pruritogens evoking pruritus symptoms, were also determined.

Results: Twenty-seven patients completed the entire course of the study. Based on the general linear model analysis, a progressive decline in the mean VAS score was observed over time during the study. The mean VAS score decreased from $8.48 \pm 1.01$ at baseline to $1.04 \pm 0.79$ at the end of treatment (P-value $<0.001)$. Similarly, the mean sleep interference scores were also significantly improved throughout treatment (decreased from $8.07 \pm 1.43$ to $2.81 \pm 0.74 ; \mathrm{P}$-value $<0.001)$. Further, at the end of the treatment, a noticeable decrement in the serum histamine level was also seen $(\mathrm{P}-\mathrm{value}=0.006)$. The drug was acceptably welltolerated and a majority of the patients were satisfied with this treatment.

Conclusion: This pilot study suggests that mirtazapine may be an effective treatment option for the management of CKD-aP. However, further studies would be needed to confirm these results.

Keywords: chronic kidney disease, renal pruritus, mirtazapine, histamine, serotonin

\section{Introduction}

Chronic kidney disease-associated pruritus (CKD-aP) is one of the most frustrating and potentially disabling symptoms among uremic patients that already burdened with chronic disease. ${ }^{1}$ It has been reported that at least $50 \%$ of patients undergoing hemodialysis (HD) treatment experience moderate or extreme CKD-aP and of
Correspondence: Vida Sheikh

Clinical Research Development Unit of Shahid Beheshti Hospital, Hamadan University of Medical Sciences, Shahid Fahmideh Ave, Hamadan 6517838678, Iran

Tel +98813821868

$\mathrm{Fax}+988138381591$

Email vsh_57072@yahoo.com 
these, $33.8 \%$ had pruritus-related sleep disorders. ${ }^{2}$ It mainly affects the face, chest, and limbs and maybe generalized in up to $50 \%$ of patients. ${ }^{3}$ It can substantially impair the patient's quality of life (QOL) because of serious discomfort, anxiety, depression, and sleeping disorders. CKD-aP has been also associated with adverse medical outcomes and is independently associated with mortality. ${ }^{1,4,5}$ Despite its high prevalence, morbidity, and marked influence on the quality of life, CKD-aP is often unreported by patients and the clinicians frequently underestimate the prevalence of pruritus among their patients. ${ }^{6,7}$ Although the pathophysiology of CKD-aP is not well understood yet, several theories on etiologic or contributing factors have been proposed. A combination of abnormalities specific to uremia including, high levels of blood urea nitrogen, elevated $\beta 2-$ microglobulin, hypervitaminosis A, high aluminum levels, anemia, erythropoietin insufficiency, elevated ferritin, low transferrin, low albumin, and secondary hyperparathyroidism with elevated divalent ions such as calcium and phosphate may have contributing roles in the etiopathogenesis of CKD-aP. Dermatological abnormalities, increased systemic inflammation and immune dysregulation, opioid-receptor derangements, and alterations in nociceptive sensory pathways in the peripheral and/or central nervous system are potential pathological pathways that are thought to be implicated in the pathogeneses of CKD-aP. ${ }^{8}$ Among possible pruritogens that can evoke pruritus symptoms, histamine is a well-known pruritogen that through $\mathrm{H} 1$ and $\mathrm{H} 4$ receptors has a role in the pathophysiology of chronic pruritus conditions like CKD-aP. ${ }^{9}$ Elevated serum level of histamine has been also observed in patients with advanced CKD suffering from pruritus. ${ }^{10}$ Serotonin is another endogenous pruritogen that has a possible role in the generation and/or sensation of CKD-aP. ${ }^{11}$ Findings from some human studies have demonstrated that serum serotonin levels were also markedly increased in patients with CKD-aP and there was a significant relationship between the presence and severity of pruritus and serotonin levels. ${ }^{12}$ Additionally, extensive researches have shown that psychotropic drugs with antagonistic effects on 5-(hydroxytryptamine) HT2 and 5HT3 receptors may have antipruritic effect in patients with chronic pruritus which further supports the possible serotonin role in the pathogenesis of pruritus. ${ }^{13}$

Due to poorly understood its pathophysiological mechanisms, optimal treatments for CKD-aP are not well defined. Kidney transplantation remains the definitive treatment in patients with end-stage kidney disease
(ESKD). Among those who are not transplantation candidates or are waiting for surgery, other therapeutic approaches to minimize the severity of pruritus such as, modification of the dialysis techniques, application of emollients, ultraviolet irradiation, acupuncture, and drug therapy should be considered. However, no treatment has been shown to have sufficient efficacy and safety and most of the CKD patients continue to suffer chronic pruritus. ${ }^{4}$ Because the mechanism of renal pruritus is likely multifactorial, the use of multiple modalities or treatment with medications with multiple anti-pruritus actions may more effectively control this difficult medical problem.

Mirtazapine is an antidepressant that exhibits both noradrenergic and serotonergic activity. By blocking 5-HT2 and 5-HT3 receptors, mirtazapine enhances 5-HT1Amediated serotonergic neurotransmission. Mirtazapine also has a high affinity for the $\mathrm{H}-1$ receptor and strongly blocks this type of histamine receptors. ${ }^{14}$ In addition to its potential usefulness in treating depression and anxiety, because to the unique mechanism of action, mirtazapine also appears to be effective in treating some other medical and neurological disorders as well as in ameliorating some of the debilitating symptoms such as weight loss, insomnia, pain, and nausea and vomiting. ${ }^{15}$ Based on its unique receptor profile, as an H1, 5HT2, and 5HT3-receptor blocker, mirtazapine may be also an option for treatment of chronic pruritus ${ }^{16}$ and some preliminary evidence has been reported regarding its potential effectiveness in reliving pruritus symptoms attributed to dermatological conditions and malignancies. ${ }^{17-19}$

Considering that the antipruritic effect of mirtazapine for the treatment of CKD-aP has not been addressed in previous studies and the little data that exists is limited to case reports, the present pilot study was conducted to estimate the efficacy and safety of mirtazapine as a possible treatment for pruritus symptoms in patients undergoing maintenance HD. We also hypothesized that mirtazapine ameliorates pruritus via decreasing serum histamine and serotonin levels in HD patients.

\section{Materials and Methods}

This was a before-after clinical trial that conducted from September 2018 until March 2019, among eligible HD patients that had been referred to the HD ward of the Shahid-Beheshti hospital, a tertiary hospital affiliated to Hamadan University of Medical Sciences, Hamadan Iran. The study was performed according to the ethical principles of the Declaration of Helsinki and its later 
amendments. After obtaining the approvals by the Ethics Committees of Hamadan University of Medical Sciences, the study was registered at the Iranian Registry of Clinical Trials (IRCT20150629022965N18). Information about the study was given to the participants and written and signed informed consent forms were obtained from those who were willing to participate.

\section{Sample Size Calculation}

A total sample size of 30 patients was calculated according to the Gill et al study ${ }^{20}$ and expected changes of the serum histamine level at least 2 as a primary variable, $\alpha=0.05$, $80 \%$ power $(1-\beta=0.8)$, and $10 \%$ possible losses to followup.

\section{Participants}

Patients were recruited in this study if the following inclusion criteria were met at baseline: patients over 18 years of age who were suffering from persistent pruritus during the past 6 weeks with mean pruritus intensity greater than 4 based on the visual analogue scale (VAS) during last week before beginning study and on maintenance HD three times a week for at least three months. The implemented exclusion criteria were as follows: kidney transplantation, anemia (hemoglobin $<7 \mathrm{~g} / \mathrm{dl}$ ), hyperparathyroidism (serum parathormone $>300 \mathrm{pg} / \mathrm{mL}$ ), serum phosphorus $>5.5 \mathrm{mg} /$ $\mathrm{dl}$, serum calcium $>10.5 \mathrm{mg} / \mathrm{dL}$ (albumin-corrected), calcium $\times$ phosphorous product $>60$, dermatologic, liver or metabolic diseases associated with pruritus, receiving chronic opiate therapy or corticosteroids, pregnancy or lactation or expecting to get pregnant during the study, being non-adherent to the treatment, consuming any antipruritic agents other than prescribed medications during study, known history of hypersensitivity to mirtazapine, and presence of any adverse effects resulting in patients' intolerance or complications.

All HD patients (106 patients) attending the HD ward of the mentioned hospital were assessed for eligibility. Of those, 36 patients did not meet the inclusion/exclusion criteria and 17 patients did not agree to take part in the study. Of the remaining 53 patients who met the study criteria and had an interest in study participation, 30 patients were selected via a random sampling method.

Required demographic and clinical data of the patients were recorded from their medical records. They included age, sex, causes of kidney disease, duration suffering from pruritus, and duration on HD therapy. Study patients received standard thrice-weekly (four hours per session) bicarbonate-based hemodialysis containing $138 \mathrm{mmol} / \mathrm{L}$ sodium, $2.5 \mathrm{mEq} / \mathrm{L}$ calcium, and $34 \mathrm{mmol} / \mathrm{L}$ bicarbonate and polysulfone dialyzer (0.8-1.3 $\mathrm{m} 2$ surface area). Blood flow and dialysate flow were $250-300$ and $500 \mathrm{~mL} / \mathrm{min}$, respectively. Dialysis efficacy was calculated using the urea kinetics model and expressed as $\mathrm{Kt} /$ Vurea and adequacy of dialysis was defined as $\mathrm{Kt} / \mathrm{V}>1.2$ (where $\mathrm{k}$ : dialyzer clearance of urea in a single treatment, in $\mathrm{mL} /$ min; t: time; V: volume of body fluid).

\section{Intervention}

Patients were required to discontinue any medication that had an antipruritic effect for two weeks before the study. After this washout period, mirtazapine (Remeron, Pfizer Pharmaceutical Company) was administered with a dosage of $15 \mathrm{mg}$ once daily, at bedtime for two weeks. Renal dose adjustment for mirtazapine was done based on the recommendations of manufacturers in HD patients and related literature. $^{21,22}$ The recommended dose of mirtazapine in HD patients is $15 \mathrm{mg}$ /day that increasing its dose above $15 \mathrm{mg} / \mathrm{d}$ should be done cautiously. Thus, we also cautiously chose a dose of $15 \mathrm{mg} /$ day in the study. Adherence to treatment was determined by counting drugs left in the container at the end of the study treatment and patients were considered adherent to treatment if at least $80 \%$ of all doses were taken.

Data on the blood levels of the hematological and biochemical parameters including, hemoglobin ( $\mathrm{Hg})$, white blood cells (WBC), Platelet (PLT), calcium, phosphorus, albumin, creatinine, and intact parathyroid hormone (iPTH) were obtained from the most recent records of routine analysis laboratory of the patients.

\section{Efficacy and Safety Assessment}

VAS was used to quantify the severity of pruritus in the study patients. VAS is one of the most commonly used methods of pruritus severity assessment. For this, a $10-\mathrm{cm}$ horizontal line was used for self-assessment of the severity of pruritus and patients were asked to rate the severity of their pruritus by crossing the line at the point that corresponded to their pruritus severity, being informed that 0 denoting no pruritus and 10 denoting worst possible imaginable pruritus. ${ }^{23}$ The severity of pruritus at baseline (before the initiation of treatment) and at each dialysis session (seven times during the 2-week treatment period) on the VAS scale was questioned and recorded. Further, the severity of pruritus was classified according to the VAS scale, in 4 steps as follows: no pruritus (VAS 0-1.0), mild 
pruritus (VAS 2.0-3.0), moderate pruritus (VAS 4.0-6.0), and severe pruritus (VAS $\geq 7.0$ ) and based on this pointing system, the severity of pruritus at baseline and the end of the treatment period was assessed. To evaluate the influence of pruritus on sleep, the patents at baseline and at each dialysis session (seven times) were asked to verbally quantify the degree of sleep interference resulting from the pruritus from 0 (does not interfere with sleep) to10 (completely interferes/unable to sleep). Furthermore, at the end of the study, all patients were asked to express their overall level of satisfaction regarding the therapy on a 4-point scale as follows: $1=$ very satisfied, $2=$ satisfied, $3=$ indifferent, and 4= unsatisfied. $^{24}$

For assessing safety and tolerability of the treatment, any reported adverse effect suspected to be associated with the use of mirtazapine from the day of first administration and at each dialysis session during 2 weeks treatment period was recorded.

\section{Measurement of Serum Histamine and Serotonin Levels}

For measurement of serum histamine and serotonin levels, $5 \mathrm{~mL}$ blood samples were drawn during the first $15 \mathrm{~min}$ utes of dialysis from each patient at the baseline (before treatment) and at the end of week 2 of the treatment protocol. The serum specimens thereafter were separated by centrifugation (10 minutes at $3000 \mathrm{rpm}$ ) and stored at $-70^{\circ} \mathrm{C}$ until analysis. In all cases, the serum levels of the biomarkers were assessed in duplicate. The serum levels of histamine and serotonin were determined according to the high-sensitivity sandwich enzyme-linked immunosorbent (ELISA) technique with immunoassay kits of ZellBio GmbH Company made of Germany and their values were expressed as nanograms per milliliter $(\mathrm{ng} / \mathrm{mL})$.

\section{Data Analysis}

Per-protocol analysis approach was used to analyze data of all individuals who completed the study. Data were analyzed using the SPSS software (version 16.0, SPSS Inc., Chicago, IL, USA). Quantitative data were expressed as mean \pm standard deviation, and qualitative data were presented as frequency and percentages. For comparison of normally distributed data, paired $t$-test was used. For nonparametric data, Mann-Whitney $U$-test was used. Chisquared test was used to compare qualitative data. Moreover, to determine the change of mean pruritus score over time and controlling the baseline differences and confounding factors, a General Linear Model (GLM) ANOVA repeated measure was used. A P-value of $<0.05$ was considered significant.

\section{Results}

\section{Demographic and Baseline}

\section{Characteristics}

$30 \mathrm{HD}$ patients who fulfilled the inclusion/exclusion criteria randomly were enrolled in this study. During the follow-up period, 3 patients (experiencing intolerable adverse effects: 1 patient and loss to follow-up: 2 patients) were excluded from the trial. All of the following results were related to 27 patients that completed the entire course of the study.

The demographic, clinical, and laboratory characteristics of the study patients are shown in Table 1. Fifteen of the patients were male $(55.6 \%)$ and twelve were female (44.4\%). Their age ranged from 37-84 years with the mean age of $61.11 \pm 10.39$ years. The main causes for which patients undergoing HD were as follows: diabetes mellitus (13 patients: 48.15\%), hypertension (7 patients: $25.93 \%$ ), and chronic glomerulonephritis (2 patients: $7.41 \%$ ). The mean duration of HD was $5.8 \pm 3.9$ years (range 1-18 years) and mean duration patients suffering from pruritus ranged from $1-10$ years $(3.5 \pm 2.8$ years $)$. Dialysis for all patients was performed at $\geq 1.2 \mathrm{Kt} / \mathrm{V}$ which indicates the adequacy of HD treatment in the study patients. As shown in Table 1, there were no critical values in the basic laboratory data characteristic of the study population that may influence the severity of pruritus.

\section{Efficacy and Safety Results}

Figure 1 and Table 2 show the mean changes in the VAS scores at different time points during the study period. Based on the general linear model analysis, there was a progressive decline in the mean VAS score at a different time point during the study. Before treatment with mirtazapine, the mean value of the VAS score was $8.48 \pm 1.01$ (range 6-10), while after a 2-week treatment it decreased to $1.04 \pm 0.79$ (range 1-6) which demonstrated statistically significant changes (difference: $-7.44 \pm 1.31$; P-value $<0.001$ ). Table 3 shows the distribution of severity of pruritus by a 4-point classification system based on the VAS score before and after a 2-week treatment with mirtazapine. Before starting the treatment, the severity of pruritus in $7(25.9 \%)$ patients was moderate (define as VAS score 4.0-6.0) and in $20(74.1 \%)$ patients was severe 
Table I The Demographic and Relevant Clinical Data of the Patients at the Beginning of the Study

\begin{tabular}{|c|c|c|}
\hline Age, Years & $\begin{array}{l}\text { Mean } \pm \text { SD } \\
\text { Range }\end{array}$ & $\begin{array}{l}61.11 \pm 10.39 \\
37-84\end{array}$ \\
\hline Sex, N (\%) & $\begin{array}{l}\text { Male } \\
\text { Female }\end{array}$ & $\begin{array}{l}15(55.6 \%) \\
12(44.4 \%)\end{array}$ \\
\hline $\begin{array}{l}\text { Causes for which patients } \\
\text { undergoing HD, } N(\%)\end{array}$ & $\begin{array}{l}\text { Diabetes mellitus } \\
\text { Hypertension } \\
\text { Chronic } \\
\text { glomerulonephritis } \\
\text { Un-known } \\
\text { Other }\end{array}$ & $\begin{array}{l}13(48.15 \%) \\
7(25.93 \%) \\
2(7.41 \%) \\
4(14.61 \%) \\
1(3.70 \%)\end{array}$ \\
\hline $\begin{array}{l}\text { Duration of HD therapy, } \\
\text { years }\end{array}$ & $\begin{array}{l}\text { Mean } \pm \text { SD } \\
\text { Range }\end{array}$ & $\begin{array}{l}5.8 \pm 3.9 \\
1-18\end{array}$ \\
\hline $\begin{array}{l}\text { Duration suffering from } \\
\text { pruritus, years }\end{array}$ & $\begin{array}{l}\text { Mean } \pm \text { SD } \\
\text { Range }\end{array}$ & $\begin{array}{l}3.5 \pm 2.8 \\
1-10\end{array}$ \\
\hline \multicolumn{3}{|c|}{ Values of relevant laboratory data } \\
\hline $\mathrm{Hg}\left(\mathrm{g} \mathrm{dL}^{-1}\right)$ & $\begin{array}{l}\text { Mean } \pm \text { SD } \\
\text { Range }\end{array}$ & $\begin{array}{l}12.25 \pm 1.91 \\
10-13.6\end{array}$ \\
\hline WBC (cell mm³ & $\begin{array}{l}\text { Mean } \pm \text { SD } \\
\text { Range }\end{array}$ & $\begin{array}{l}5230 \pm 2340 \\
2500-8200\end{array}$ \\
\hline $\operatorname{PLT}\left(10^{3} \mu \mathrm{L}^{-1}\right)$ & $\begin{array}{l}\text { Mean } \pm \text { SD } \\
\text { Range }\end{array}$ & $\begin{array}{l}213.45 \pm 85.60 \\
138-427\end{array}$ \\
\hline Calcium (mg dL ${ }^{-1}$ ) & $\begin{array}{l}\text { Mean } \pm \text { SD } \\
\text { Range }\end{array}$ & $\begin{array}{l}8.85 \pm 0.62 \\
6.9-9.8\end{array}$ \\
\hline Phosphorus (mg dL ${ }^{-1}$ ) & $\begin{array}{l}\text { Mean } \pm \text { SD } \\
\text { Range }\end{array}$ & $\begin{array}{l}4.75 \pm 0.58 \\
2.8-4.8\end{array}$ \\
\hline Albumin $\left(\mathrm{g} \mathrm{dL}^{-1}\right)$ & $\begin{array}{l}\text { Mean } \pm \text { SD } \\
\text { Range }\end{array}$ & $\begin{array}{l}3.74 \pm 0.58 \\
3.3-5.2\end{array}$ \\
\hline iPTH $\left(\mathrm{g} \mathrm{dL}^{-1}\right)$ & $\begin{array}{l}\text { Mean } \pm \text { SD } \\
\text { Range }\end{array}$ & $\begin{array}{l}249.22 \pm 80.15 \\
150-350\end{array}$ \\
\hline $\mathrm{KeV}^{-1}$ & $\begin{array}{l}\text { Mean } \pm \text { SD } \\
\text { Range }\end{array}$ & $\begin{array}{l}1.29 \pm 0.08 \\
1.2-1.5\end{array}$ \\
\hline Creatinine $\left(\mathrm{mg} \mathrm{dL}^{-1}\right)$ & $\begin{array}{l}\text { Mean } \pm \text { SD } \\
\text { Range }\end{array}$ & $\begin{array}{l}8.8 \pm 3.8 \\
5.9-12.3\end{array}$ \\
\hline
\end{tabular}

Abbreviations: $\mathrm{HD}$, hemodialysis; $\mathrm{Hg}$, hemoglobin; WBC, white blood cells; PLT, Platelet; iPTH, intact parathyroid hormone; $\mathrm{Kt}^{-1}$, Kt stands for dialyzer clearance multiplied by time $\left(\mathrm{mL} \mathrm{min}^{-1}\right)$ and $\mathrm{V}$ for volume of water a patient's body contains.

(define as VAS score $\geq 7.0$ ). After 2-week treatment with mirtazapine, severity of pruritus in $7(25.9 \%)$ patients was no pruritus (define as VAS score 0-1.0), in $17(63 \%)$ patients was mild (define as VAS score 1.0-3.0), and only $3(11.1 \%)$ patients had moderate pruritus (define as

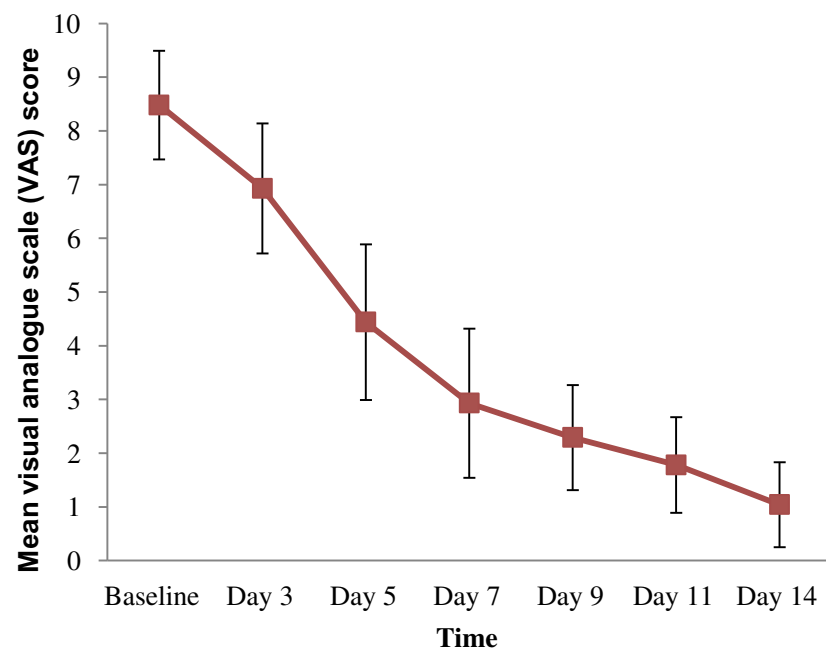

Figure I Changes of pruritus severity based on the visual analogue scale (VAS) at different time points during the study $(P$-value $<0.001)$.

VAS score 4.0-6.0). Therefore, as shown in Table 3, compared to the starting of the treatment, the severity of pruritus was improved after therapy with mirtazapine that was statistically significant (P-value $<0.001)$.

Similarly to the VAS scores, the mean sleep interference scores (SIS) resulting from the pruritus were also significantly improved over the course of the treatment (Figure 2 and Table 2). Mean SIS reduced from 8.07 \pm 1.43 at baseline to $2.81 \pm 0.74$ at the end of therapy (difference: $-5.25 \pm 1.61$; P-value $<0.001$ ).

In respect of the occurrence of adverse effects, 9 cases experienced adverse effects (4 cases reported drowsiness, 2 cases reported dry mouth, one case reported headache, and 2 cases reported dizziness); nevertheless, only one case discontinued the mirtazapine due to the experiencing intolerable drowsiness. As these adverse effects were mild, none of the reported adverse effects was serious or caused any complication for the patients.

Table 2 The Values of VAS and SIS at Different Time Points During the Study

\begin{tabular}{|l|l|l|l|l|}
\hline Time & VAS scores & P-Value & SIS scores & P-Value \\
\hline Day I & $8.48 \pm 1.01$ & & $8.07 \pm 1.43$ & \\
Day 3 & $6.93 \pm 1.21$ & & $6.06 \pm 1.07$ & \\
Day 5 & $4.44 \pm 1.45$ & $<0.001$ & $5.22 \pm 1.15$ & $<0.001$ \\
Day 7 & $2.93 \pm 1.39$ & & $4.44 \pm 0.97$ & \\
Day 9 & $2.29 \pm 0.98$ & & $4.11 \pm 1.01$ & \\
Day II & $1.78 \pm 0.89$ & & $3.41 \pm 0.92$ & \\
Day 14 & $1.04 \pm 0.79$ & & $2.81 \pm 0.74$ & \\
\hline
\end{tabular}

Note: Values represent as mean \pm SD.

Abbreviations: VAS, visual analogue scale; SIS, sleep interference score. 
Table 3 Distribution of Severity of Pruritus by 4-Point Classification System Before and After Treatment with Mirtazapine

\begin{tabular}{|l|l|l|l|l|l|}
\hline $\begin{array}{l}\text { VAS } \\
\text { Severity }\end{array}$ & $\begin{array}{l}\text { None } \\
\text { n (\%) }\end{array}$ & $\begin{array}{l}\text { Mild } \\
\mathbf{n}(\%)\end{array}$ & $\begin{array}{l}\text { Moderate } \\
\mathbf{n}(\%)\end{array}$ & $\begin{array}{l}\text { Severe } \\
\text { n (\%) }\end{array}$ & P-value \\
\hline $\begin{array}{l}\text { Before } \\
\text { treatment }\end{array}$ & $0(0)$ & $0(0)$ & $7(25.9)$ & $20(74.1)$ & $<0.001$ \\
$\begin{array}{l}\text { After } \\
\text { treatment }\end{array}$ & 7 & $\begin{array}{l}17 \\
(25.9)\end{array}$ & $3(11.2)$ & $0(0)$ & \\
\hline
\end{tabular}

Moreover, regarding the satisfaction with treatment, at the end of the study, the majority of the patients ( 21 cases, $77.8 \%$ ) were "very satisfied" or "satisfied" with treatment and 6 patients $(22.2 \%)$ were indifferent. Importantly, dissatisfaction with treatment was not reported by any of the study patients. Therefore, overall satisfaction with treatment was relatively high among the study patients.

\section{Changes in Serum Histamine and Serotonin Levels}

The results regarding changes in the serum histamine and serotonin levels are presented in Table 4. As showed, before treatment with mirtazapine the mean serum histamine and serotonin levels were $25.40 \pm 8.21$ and 92.44 \pm 27.79 respectively. Compared to the starting of the treatment at the end of the treatment period a noticeable decrement on serum histamine level was seen that its change was statistically significant (decreased from $25.40 \pm 8.21$ at baseline to $22.48 \pm 7.07$ at the end of the treatment period;

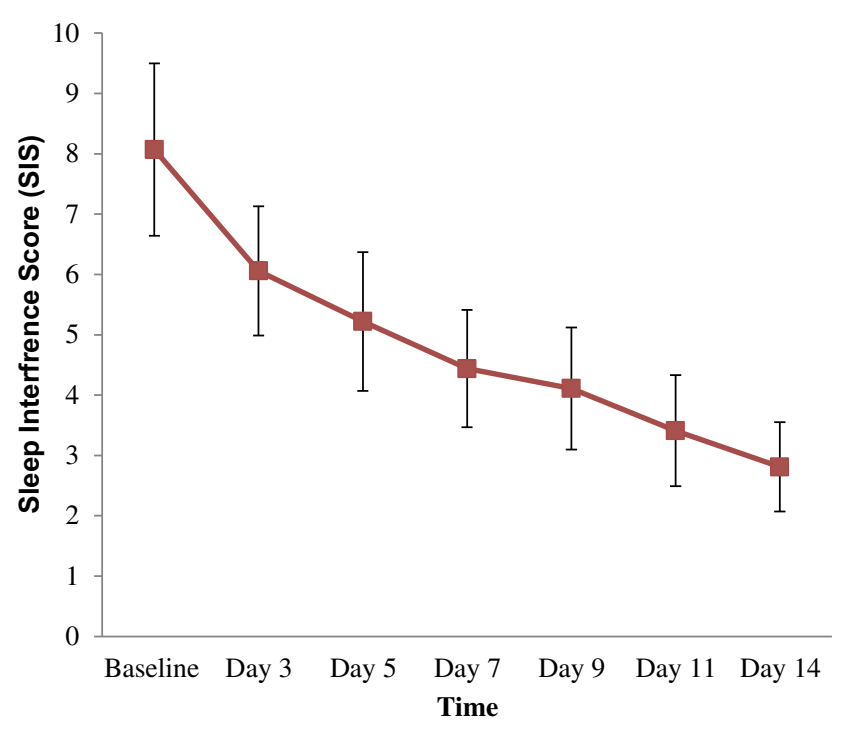

Figure 2 Mean sleep interference score at different time points during the study period (P-value $<0.00 \mathrm{I})$.
Table 4 Serum Levels of Histamine and Serotonin Before and After the Treatment

\begin{tabular}{|l|l|l|l|}
\hline Variable & $\begin{array}{l}\text { Before } \\
\text { Treatment }\end{array}$ & $\begin{array}{l}\text { After } \\
\text { Treatment }\end{array}$ & P-value \\
\hline Histamine $(\mathrm{ng} / \mathrm{mL})$ & $25.40 \pm 8.21$ & $22.48 \pm 7.07$ & 0.006 \\
Serotonin $(\mathrm{ng} / \mathrm{mL})$ & $92.44 \pm 27.79$ & $85.80 \pm 30.67$ & 0.10 \\
\hline
\end{tabular}

Note: Values represented as mean \pm SD.

P-value $=0.006$ ). Although, after 2 weeks of treatment the serum serotonin level was also decreased compared to the beginning of the study, its changes did not reach the significant level $(\mathrm{P}$-value $=0.10)$.

\section{Discussion}

To the best of our knowledge, this is the first clinical study evaluating the antipruritic effect of mirtazapine in HD patients. This pilot before-after clinical trial demonstrated that mirtazapine use at a dose of $15 \mathrm{mg}$ daily is associated with an improvement in CKD-aP and sleep interference score resulting from pruritus. Importantly, the drug was acceptably well-tolerated in the patients and at the end of the study the majority of the patients were satisfied with this treatment. Moreover, the decline in the serum histamine level showed the clinical efficacy of mirtazapine may be mediated at least in part, through this pathway.

Among main chemical pruritogens, histamine, serotonin, and endogenous opioids have key contributory roles in the pathogeneses of pruritus. Releases of these mediators by activating a subset of unmyelinated C-fibres in the dermalepidermal junction that transmit the signal to the central nervous system evoke sensations of pruritus. ${ }^{25,26}$ Increased expression of 5-HT receptors and serotonin transporter protein on skin cells is closely associated with a typical itchy disorder such as allergic contact dermatitis and atopic dermatitis. ${ }^{27,28}$ Increased serum levels of histamine and serotonin have been also reported in HD patients with pruritus. ${ }^{10,29}$ It is hypothesized that serotonin at the periphery, indirectly by stimulating histamine release from mast cells and at the central nervous system, through opioids participation leads to pruritus generation. $^{30,31}$ Related research in renal pruritus also have demonstrated that endogenous opioids imbalance between the activities of the most antagonistic acting $\mu$ - and $\kappa$-opioid receptors in favor of $\mu$-receptor activation has been implicated in the pathogenesis of CKD-aP. ${ }^{29,32}$ Thus, taking into consideration these causative mechanisms, antagonizing the activity of these chemical pruritogens may have a potential beneficial effect in the pharmacological management of CKD-aP. 
Mirtazapine as a noradrenergic and specific serotonergic antidepressant is clinically used in the treatment of depression or anxiety disorders. ${ }^{33}$ On account of its unique receptor profile and mechanism of action, the use of the mirtazapine in a wide range of pathological conditions has been growing. Preliminary evidence also has been raised regarding its potential effectiveness in the management of pruritus. To date, only in case reports and small case series potential antipyretic effects of mirtazapine have been reported. Davis et al reported mirtazapine at doses ranging from 15 to $30 \mathrm{mg}$ per day was effective in treating pruritus in four patients suffering from adenocarcinoma and multiple liver metastases, Hodgkin's disease, chronic lymphocytic leukemia, and renal cancer. ${ }^{34}$ Marked improvement in nocturnal and daytime pruritus symptoms was also observed after treatment with mirtazapine $(15 \mathrm{mg}$ once daily) in a series of patients with inflammatory skin diseases suffering from severe resistant nocturnal pruritus. ${ }^{35}$ Kulaç et al also reported a significant response with the usage of oral mirtazapine in three patients with persistent chronic urticarial. ${ }^{17}$ Further, in two case reports mirtazapine was used as an effective agent in the management of debilitating pruritus associated with cutaneous metastatic of carcinoma en cuirasse as well as cutaneous T-cell lymphoma. ${ }^{18,19}$ However, there is a paucity of clinical trials by the use of mirtazapine in the treatment of pruritus and only in one randomized control clinical trial, the effect of preoperative mirtazapine administration on intrathecal morphine-induced pruritus has been investigated. Results of this study showed premedication with mirtazapine can reduce the incidence, severity, and duration of postoperative pruritus induced by intrathecal morphine administration. ${ }^{36}$ Herein, we also showed that mirtazapine treatment effectively treated pruritus symptoms in HD patients.

On the basis of its pharmacologic profile, mirtazapine at least, in theory, have a number of possible mechanisms of action in the treatment of pruritus. It seems the antipruritic effects of mirtazapine mainly stem from its strong antagonistic activity against central and cutaneous receptors of serotonin $(5 \mathrm{HT} 2,5 \mathrm{HT} 3)$ and histamine $(\mathrm{H} 1)$ that are known as major receptors associated with pruritus. ${ }^{34}$ Further, it is hypothesized that mirtazapine via antagonism of central alpha-2-auto- and hetero-adrenoreceptors may inhibit the neuronal transmission during itch processing. ${ }^{35}$ Additionally, in an experimental study, it was found that 5HT3-receptor antagonists like mirtazapine may have inhibitory effects on histamine release from mast cells. ${ }^{37}$
Consistent with this, in the percent study, we also observed mirtazapine significantly reduced serum levels of histamine. Considering possible involvement of the opioid system in the pathogenesis of renal pruritus, large numbers of experimental and human studies have focused on the effects of kappa-opioid agonists as a novel therapeutic modality in the management of CKD-aP. ${ }^{38,39}$ Preliminary evidence demonstrated that mirtazapine can also act as a kappa-opioid receptor agonist agent in the central nervous system. ${ }^{40}$ Therefore, it is assumed that the activation of the $\kappa$-opioid system is another potential mechanism that may be responsible for the antipruritic effects of mirtazapine. Apart from these mechanisms, given that stress exacerbates pruritus, the antianxiety property of mirtazapine may also indirectly attenuate pruritus sensation. ${ }^{15}$

In addition to effectiveness for the treatment of pruritus, based on its mechanisms of action, mirtazapine can have other potentially beneficial effects in patients with CKD, particularly in HD patients. Increased appetite and weight gain induced by mirtazapine which is a common side-effect of mirtazapine ${ }^{41}$ can be advantageous in HD patients that anorexia and weight loss are relatively common among them. ${ }^{42}$ Nevertheless, considering that diabetes mellitus is a common cause of $\mathrm{CKD},{ }^{43}$ one important consideration in selecting an antipruritic agent in diabetic patients with CKD is the potential impact of the agent on appetite, total body weight, blood sugar, and cholesterol. So, potential negative impact of mirtazapine on blood sugar control and serum lipid profiles should be considered in diabetic patients. However, on the other hand, because of impaired renal gluconeogenesis, malnutrition, chronic inflammation, decrease renal insulin clearance, and the increased half-life of hypoglycemic agents, hypoglycemia is common among ESRD patients. ${ }^{44}$ Moreover, a previous study on mirtazapine in diabetic patients reported at least in the short-term (less than 6 months), mirtazapine is safe for diabetic patients in a stable state and undergoing appropriate diabetic treatment ${ }^{45}$ and even one study reported that non-diabetic depressive patients taking mirtazapine for 2 to 6 weeks gained weight but exhibited improved glucose tolerance. ${ }^{46}$ Because of its unique characteristic of antagonizing 5-HT3 receptors, mirtazapine also may alleviate nausea and vomiting that are common complications during HD treatment. ${ }^{47}$ Additionally, given that somnolence being one of the most common side effects of mirtazapine, its beneficial effects in the treatment of insomnia without potential risk for dependency, respiratory suppression, or 
disturbance of deep-stage sleep have been reported. ${ }^{15}$ Therefore, mirtazapine may be also attractive treatment option in improving the quality and quantity of sleep in patients with CKD who have high-frequency insomnia problems. ${ }^{48}$ Pain has been also reported to be a common problem among patients with CKD that affects $>60-70 \%$ of patients with advanced kidney disease. ${ }^{49}$ Preliminary experimental and clinical data have also demonstrated the potential beneficial effect of mirtazapine in the treatment of pain associated with a wide array of etiologies. ${ }^{50,51}$ However, despite this evidence, to date yet the potential effectiveness of mirtazapine on these symptoms in patients with CKD has not been assessed in clinical trials and needs to be investigated in future studies.

Additional advantage of mirtazapine is its little potential to interact with other drugs. Further, because its elimination half-life is approximately one day, mirtazapine can be given once daily which enhances patients' compliance. ${ }^{14}$ These properties may be also useful especially in HD patient population who often require the use of several medications. $^{52}$

Despite the novelty of the findings, we acknowledge several limitations of the present study. Our study was a before-after not a placebo-controlled clinical trial with a relatively small sample size and short follow-up period that may influence the results. Further, sleep interference resulting from pruritus was evaluated only by a single question instead of using validated instruments such as the Athens insomnia scale ${ }^{53}$ and Pittsburg sleep quality index. ${ }^{54}$ Moreover, only two samples were taken from each patient at baseline and at the end of the treatment period. Therefore, the quality of the data does not allow a deeper inspection and understanding of the biochemical changes of biomarkers. Additionally, the statistical data analysis was performed per protocol, while an intent-to-treat analysis might have allowed observing a modified pattern of results. Therefore, further studies using a randomized controlled-placebo design in larger sample size and longer follow up period are needed to confirm these observations.

\section{Conclusion}

Together, this pilot study suggests that mirtazapine may be an effective option for the treatment of CKD-aP and sleep interference resulting from pruritus in patients undergoing HD. It is possible that the antipruritic effect of mirtazapine at least in part is attributed to its ameliorative effect on serum histamine levels. However, further studies would be needed to establish the potential therapeutic effects of mirtazapine in the management of CKD-aP.

\section{Data Sharing Statement}

The datasets used and/or analyzed during the current study are available from the corresponding author on reasonable request up to 2 years after publication.

\section{Acknowledgments}

This study was supported by the Vice-Chancellor of Research and Technology of Hamadan University of Medical Sciences, Hamadan, Iran (No: 9705233062). The authors thank all patients for helping and participating in the study.

\section{Disclosure}

The authors report no conflicts of interest in this study.

\section{References}

1. Pisoni RL, Wikström B, Elder SJ, et al. Pruritus in haemodialysis patients: international results from the Dialysis Outcomes and Practice Patterns Study (DOPPS). Nephrol Dial Transplant. 2006;21(12):3495-3505. doi:10.1093/ndt/gfl461

2. Mettang T, Kremer AE. Uremic pruritus. Kidney Int. 2015;87 (4):685-691. doi:10.1038/ki.2013.454

3. Shirazian S, Aina O, Park Y, et al. Chronic kidney disease-associated pruritus: impact on quality of life and current management challenges. Int J Nephrol Renovasc Dis. 2017;10:11. doi:10.2147/ IJNRD.S108045

4. Simonsen E, Komenda P, Lerner B, et al. Treatment of uremic pruritus: a systematic review. Am J Kidney Dis. 2017;70 (5):638-655. doi:10.1053/j.ajkd.2017.05.018

5. Narita I, Alchi B, Omori K, et al. Etiology and prognostic significance of severe uremic pruritus in chronic hemodialysis patients. Kidney Int. 2006;69(9):1626-1632. doi:10.1038/sj.ki.5000251

6. Weisbord SD, Fried LF, Mor MK, et al. Renal provider recognition of symptoms in patients on maintenance hemodialysis. Clin J Am Soc Nephrol. 2007;2(5):960-967. doi:10.2215/CJN.00990207

7. Weisshaar E, Matterne U, Mettang T. How do nephrologists in haemodialysis units consider the symptom of itch? Results of a survey in Germany. Nephrol Dial Transplant. 2009;24 (4):1328-1330. doi:10.1093/ndt/gfn769

8. Lugon JR. Uremic pruritus: a review. Hemodial Int. 2005;9 (2):180-188. doi:10.1111/j.1492-7535.2005.01130.x

9. Grundmann S, Ständer S. Chronic pruritus: clinics and treatment. Ann Dermatol. 2011;23(1):1-11. doi:10.5021/ad.2011.23.1.1

10. Stockenhuber F, Kurz RW, Sertl K, Grimm G, Balcke P. Increased plasma histamine levels in uraemic pruritus. Clin Sci. 1990;79 (5):477-482. doi:10.1042/cs0790477

11. Mysliwiec H, Pawlak D, Serwin A, Mysliwiec P, Mysliwiec M, Chodynicka B. The role of serotonin and tryptophan in uremic pruritus in hemodialysed patients. Przegl Dermatol. 2006;93(1):61.

12. Balaskas EV, Bamihas GI, Karamouzis M, Voyiatzis G, Tourkantonis A. Histamine and serotonin in uremic pruritus: effect of ondansetron in CAPD-pruritic patients. Nephron. 1998;78 (4):395-402. doi:10.1159/000044967 
13. Schwörer H, Ramadori G. Treatment of pruritus: a new indication for serotonin type 3 receptor antagonists. Clin Investig. 1993;71 (8):659-662. doi:10.1007/BF00184497

14. Anttila SA, Leinonen EV. A review of the pharmacological and clinical profile of mirtazapine. CNS Drug Rev. 2001;7(3):249-264. doi:10.1111/j.1527-3458.2001.tb00198.x

15. Alam A, Voronovich Z, Carley JA. A review of therapeutic uses of mirtazapine in psychiatric and medical conditions. Prim Care Companion CNS Disord. 2013;15(5).

16. Khanna R, Boozalis E, Belzberg M, Zampella JG, Kwatra SG. Mirtazapine for the treatment of chronic pruritus. Medicines. 2019;6 (3):73. doi:10.3390/medicines6030073

17. Kulaç M, Karaca Ş, Özbulut Ö, Çetişli A. Oral mirtazapine in persistent chronic urticaria. TURKDERM-Arch Turkish Dermatol Venerol. 2008;42(1):31-33.

18. Lee JJ, Girouard SD, Carlberg VM, Mostaghimi A. Effective use of mirtazapine for refractory pruritus associated with carcinoma en cuirasse. BMJ Support Palliat Care. 2016;6(1):119-121. doi:10.1136/bmjspcare-2014-000790

19. Demierre M-F, Taverna J. Mirtazapine and gabapentin for reducing pruritus in cutaneous T-cell lymphoma. $J$ Am Acad Dermatol. 2006;55(3):543-544. doi:10.1016/j.jaad.2006.04.025

20. Gill D, Fonseca V, Barradas M, Balliod R, Moorhead J, Dandona P. Plasma histamine in patients with chronic renal failure and nephrotic syndrome. J Clin Pathol. 1991;44(3):243-245. doi: $10.1136 /$ jep. 44.3 .243

21. Eyler RF, Unruh ML, Quinn DK, Mary Vilay A. Psychotherapeutic agents in end-stage renal disease. Semin Dial. 2015.;28(4):417-426

22. Nagler EV, Webster AC, Vanholder R, Zoccali C. Antidepressants for depression in stage 3-5 chronic kidney disease: a systematic review of pharmacokinetics, efficacy and safety with recommendations by European Renal Best Practice (ERBP). Nephrol Dial Transplant 2012;27(10):3736-3745. doi:10.1093/ndt/gfs295

23. Reich A, Heisig M, Phan NQ, et al. Visual analogue scale: evaluation of the instrument for the assessment of pruritus. Acta Derm Venereol. 2012;92(5):497-501. doi:10.2340/00015555-1265

24. Takahashi N, Yoshizawa T, Kumagai J, et al. Response of patients with hemodialysis-associated pruritus to new treatment algorithm with nalfurafine hydrochloride: a retrospective survey-based study. Ren Replace Ther. 2016;2(1):27. doi:10.1186/s41100-016-0039-x

25. Feramisco JD, Berger TG, Steinhoff M. Innovative management of pruritus. Dermatol Clin. 2010;28(3):467-478. doi:10.1016/j. det.2010.03.004

26. Kremer AE, Elferink RPO, Beuers U. Pathophysiology and current management of pruritus in liver disease. Clin Res Hepatol Gastroenterol. 2011;35(2):89-97. doi:10.1016/j.clinre.2010.10.007

27. El-Nour H, Lundeberg L, Abdel-Magid N, Lonne-Rahm S-B, C Azmitia E, Nordlind K. Serotonergic mechanisms in human allergic contact dermatitis. Acta Derm Venereol. 2007;87(5):390-396. doi: 10.2340/00015555-0288

28. Lonne-Rahm SB, Rickberg H, El-Nour H, Mårin P, Azmitia E, Nordlind K. Neuroimmune mechanisms in patients with atopic dermatitis during chronic stress. J Eur Acad Dermatol Venereol. 2008;22 (1):11-18. doi:10.1111/j.1468-3083.2007.02202.x

29. Manenti L, Tansinda P, Vaglio A. Uraemic pruritus. Drugs. 2009;69 (3):251-263. doi:10.2165/00003495-200969030-00002

30. Charuluxananan S, Kyokong O, Somboonviboon W, Narasethakamol A, Promlok P. Nalbuphine versus ondansetron for prevention of intrathecal morphine-induced pruritus after cesarean delivery. Anesth Analg. 2003;96(6):1789-1793. doi:10.1213/01. ANE.0000066015.21364.7D

31. Parada C, Tambeli C, Cunha F, Ferreira S. The major role of peripheral release of histamine and 5-hydroxytryptamine in formalin-induced nociception. Neuroscience. 2001;102(4):937-944. doi:10.1016/S0306-4522(00)00523-6
32. Umeuchi H, Togashi $\mathrm{Y}$, Honda $\mathrm{T}$, et al. Involvement of central $\mu$ opioid system in the scratching behavior in mice, and the suppression of it by the activation of $\kappa$-opioid system. Eur J Pharmacol. 2003;477 (1):29-35. doi:10.1016/j.ejphar.2003.08.007

33. Croom KF, Perry CM, Plosker GL. Mirtazapine. CNS Drugs. 2009;23 (5):427-452. doi:10.2165/00023210-200923050-00006

34. Davis MP, Frandsen JL, Walsh D, Andresen S, Taylor S. Mirtazapine for pruritus. J Pain Symptom Manage. 2003;25(3):288-291. doi:10.1016/S0885-3924(02)00645-0

35. Hundley JL, Yosipovitch G. Mirtazapine for reducing nocturnal itch in patients with chronic pruritus: a pilot study. J Am Acad Dermatol. 2004;50(6):889-891. doi:10.1016/j.jaad.2004.01.045

36. Alhashemi JA, Crosby ET, Grodecki W, Duffy PJ, Hull KA, Gallant C. Treatment of intrathecal morphine-induced pruritus following caesarean section. Can J Anaesth. 1997;44(10):1060. doi:10.1007/BF03019227

37. Weisshaar E, Ziethen B, Röhl FW, Gollnick H. The antipruritic effect of a 5-HT3 receptor antagonist (tropisetron) is dependent on mast cell depletion-an experimental study. Exp Dermatol. 1999;8(4):254-260. doi:10.1111/j.1600-0625.1999.tb00379.x

38. Chavkin C. The therapeutic potential of $\kappa$-opioids for treatment of pain and addiction. Neuropsychopharmacology. 2011;36(1):369. doi:10.1038/npp.2010.137

39. Wikström B, Gellert R, Ladefoged SD, et al. $\kappa$-Opioid system in uremic pruritus: multicenter, randomized, double-blind, placebocontrolled clinical studies. Clin J Am Soc Nephrol. 2005;16 (12):3742-3747. doi:10.1681/ASN.2005020152

40. Schreiber S, Rigai T, Katz Y, Pick CG. The antinociceptive effect of mirtazapine in mice is mediated through serotonergic, noradrenergic and opioid mechanisms. Brain Res Bull. 2002;58(6):601-605. doi:10.1016/S0361-9230(02)00825-0

41. Montgomery S. Safety of mirtazapine: a review. Int Clin Psychopharmacol. 1995;10(Supplement 4):37-45. doi:10.1097/ 00004850-199512004-00006

42. Bossola M, Tazza L, Giungi S, Luciani G. Anorexia in hemodialysis patients: an update. Kidney Int. 2006;70(3):417-422. doi:10.1038/sj. ki.5001572

43. Evans PD, Taal MW. Epidemiology and causes of chronic kidney disease. Medicine. 2015;43(8):450-453. doi:10.1016/j. mpmed.2015.05.005

44. Park J, Lertdumrongluk P, Molnar MZ, Kovesdy CP, Kalantar-Zadeh $\mathrm{K}$. Glycemic control in diabetic dialysis patients and the burnt-out diabetes phenomenon. Curr Diab Rep. 2012;12(4):432-439. doi:10.1007/s11892-012-0286-3

45. Song HR, Woo YS, Wang H-R, Shim I-H, Jun T-Y, Bahk W-M. Does mirtazapine interfere with naturalistic diabetes treatment? J Clin Psychopharmacol. 2014;34(5):588-594. doi:10.1097/JCP.000000 0000000183

46. Himmerich H, Fulda S, Schaaf L, Beitinger PA, Schuld A, Pollmacher T. Changes in weight and glucose tolerance during treatment with mirtazapine. Diabetes Care. 2006;29(1):170-171. doi:10.2337/diacare.29.01.06.dc05-1762

47. Asgari MR, Asghari F, Ghods AA, Ghorbani R, Motlagh NH, Rahaei F. Incidence and severity of nausea and vomiting in a group of maintenance hemodialysis patients. J Renal Inj Prev. 2017;6(1):49. doi:10.15171/jrip.2017.09

48. Violani C, Lucidi F, Devoto A, Lombardo C, De Santo RM. Insomnia and its comorbidities in chronic kidney disease. Semin Nephrol. 2006;26:61-63.

49. Pham PC, Khaing K, Sievers TM, et al. 2017 update on pain management in patients with chronic kidney disease. Clin Kidney J. 2017;10 (5):688-697. doi:10.1093/ckj/sfx080

50. Zhu J, Wei X, Feng X, Song J, Hu Y, Xu J. Repeated administration of mirtazapine inhibits development of hyperalgesia/allodynia and activation of NF- $\mathrm{BB}$ in a rat model of neuropathic pain. Neurosci Lett. 2008;433(1):33-37. doi:10.1016/j.neulet.2007.12.037 
51. Theobald DE, Kirsh KL, Holtsclaw E, Donaghy K, Passik SD. An open-label, crossover trial of mirtazapine (15 and $30 \mathrm{mg}$ ) in cancer patients with pain and other distressing symptoms. J Pain Symptom Manage. 2002;23(5):442-447. doi:10.1016/S0885-3924(02)00381-0

52. Rama M, Viswanathan G, Acharya LD, Attur R, Reddy P, Raghavan S. Assessment of drug-drug interactions among renal failure patients of nephrology ward in a South Indian tertiary care hospital. Indian J Pharm Sci. 2012;74(1):63. doi:10.4103/0250474X.102545
53. Soldatos CR, Dikeos DG, Paparrigopoulos TJ. Athens insomnia scale: validation of an instrument based on ICD-10 criteria. $J$ Psychosom Res. 2000;48(6):555-560. doi:10.1016/S0022-39 99(00)00095-7

54. Buysse DJ, Reynolds III CF, Monk TH, Berman SR, Kupfer DJ. The Pittsburgh sleep quality index: a new instrument for psychiatric practice and research. Psychiatry Res. 1989;28(2):193-213. doi:10.1016/0165-1781(89)90047-4

\section{Publish your work in this journal}

The International Journal of Nephrology and Renovascular Disease is an international, peer-reviewed open-access journal focusing on the pathophysiology of the kidney and vascular supply. Epidemiology, screening, diagnosis, and treatment interventions are covered as well as basic

Submit your manuscript here: https://www.dovepress.com/international-journal-of-nephrology-and-renovascular-disease-journal science, biochemical and immunological studies. The manuscript management system is completely online and includes a very quick and fair peer-review system, which is all easy to use. Visit http://www.dovepress.com/testimonials.php to read real quotes from published authors. 